\title{
Proposed Testing Quality of Silicon Nitride in Nuclear Application by Ceramography
}

\section{Tjokorda Gde Tirta Nindhia}

Department of Mechanical Engineering, Engineering Faculty, Udayana University, Jimbaran, Bali, Indonesia, 80361

\section{Abstract}

The components in nuclear application should ensure the safety during operation. Testing and investigation should be performed to ensure the quality of every component. This report propose ceramography technique for testing of silicon nitride in nuclear application. Ceramic material is known brittle therefore not possible to hold by using vice as usual used in metal during cutting. Since ceramic is very hard, the cost for cutting, grinding and polishing required high cost due to utilization of diamond. Special techniques should be employed during observation bay using optical microscope because ceramic are not reflect the light. Ceramic is mainly known since their high chemical resistance therefore difficult to etching by using chemical solution. A unique respond of ceramic due to indentation make the indentation technique become

Corresponding Author: Tjokorda Gde Tirta Nindhia, email: nindhia@yahoo.com

Received: 29 July 2016 Accepted: 21 August 2016 Published: 21 September 2016

\section{Publishing services} provided by Knowledge E

(c) Tjokorda Gde Tirta Nindhia. This article is distributed under the terms of the Creative Commons Attribution License, which permits unrestricted use and redistribution provided that the original author and source are credited.

Selection and Peer-review under the responsibility of the ICONETS Conference Committee.

\section{OPEN ACCESS} part of ceramography. Indentation process requires a flat sample in order valid result to be obtained, and this can be achieved by special technique during grinding and polishing. This research introduce of ceramography process that was successfully done on $\mathrm{Siz}_{4}$, from preparation of the specimen, microstructure observation, the respond on indentation, strength, and porosity investigation. The results showed that the fluorescent dye penetrant under ultra violet source of light the defect in $\mathrm{Si}_{3} \mathrm{~N}_{4}$ was easily observed therefore is suitable to be proposed as a technique for testing the quality of silicon nitride component in nuclear application.

Keywords: ceramography, ceramic, silicon nitride, nuclear application, indentation

\section{Introduction}

Silicon nitride $\left(\mathrm{Si}_{3} \mathrm{~N}_{4}\right.$ ) is an advanced ceramic that mostly used in high-endurance and temperature applications, such as gas turbines, metal working, cutting tools and even more for application where maximum fracture toughness is required such as for seal face in nuclear application. It is also superior wear resistance, therefore excellent as bearings. Modern industry and transportation run on bearing. Bearing provide rolling contact rather than sliding contact and thus greatly decrees wear and friction. To be viable for bearing, a material must be hard and tough to resist the high Herzian contact loads to which a bearing is exposed. It must also be capable of fabrication to high smoothness and close tolerance and operate with low coefficient of friction against a mating surface. The $\mathrm{Si}_{3} \mathrm{~N}_{4}$ bearing did not fail catastrophically like prior ceramics. Instead, they failed by slow development of surface spallation very similar to the failure mode of metal. The reason 
for this was determined to be the higher level of fracture toughness. A very important factor compared to metals is that $\mathrm{Si}_{3} \mathrm{~N}_{4}$ has approximately $40 \%$ of the specific gravity of steel that substantial reduction in stress for a given bearing size [1].

Ceramography is the art and science of preparation, examination, and evaluation of ceramic microstructure. The microstructure is the structure level approximately 0.1 to 100 $\mu \mathrm{m}$ between the wavelength of the visible light and the resolution limit of the naked eye. The microstructures include most grain, secondary phase, grain boundaries, pore, micro crack and hardness micro indentation. The $100 \mu \mathrm{m}$ level is approximately the limit of resolution by the unaided human eye. The structure level larger that $100 \mu \mathrm{m}$ is sometimes called the macrostructure, and some ceramic have grains and pores that are visible to the naked eye. A microscope cannot solve anything significantly smaller than the wave length of visible light 360 to $780 \mathrm{~nm}$, or roughly $0.4 \mu \mathrm{m}$. The electron microscope, which use beam electron rather that visible light to generate image, are well suited for observation of micro structural features that are smaller than the wavelength of visible light [2].

This research introduce of ceramography process that was successfully done on $\mathrm{Si}_{3} \mathrm{~N}_{4^{\prime}}$ from preparation of the specimen, microstructure observation, the respond on indentation, strength, and porosity investigation. The ceramography process is expected to be used as a technique to test the quality of the silicon nitride component in nuclear applications.

\section{Methodology}

The material use for this research was $\mathrm{Si}_{3} \mathrm{~N}_{4}$ produced by CeramTec (Plochingen, Germany) under the name SL200 B. It is a gas pressure sintered ceramic containing $3 \mathrm{wt} . \% \mathrm{Al}_{2} \mathrm{O}_{3}$ and 3 wt. $\% \mathrm{Y}_{2} \mathrm{O}_{3}$. The material was cut by using diamond wheel (Fig. 1) with about the same thickness and mounted at upper disc of polishing machine (Fig. 2) by using thermoplastic glue (Fig. 3). For this purpose the disc should be heated by using hot plate in order to melt the glue.

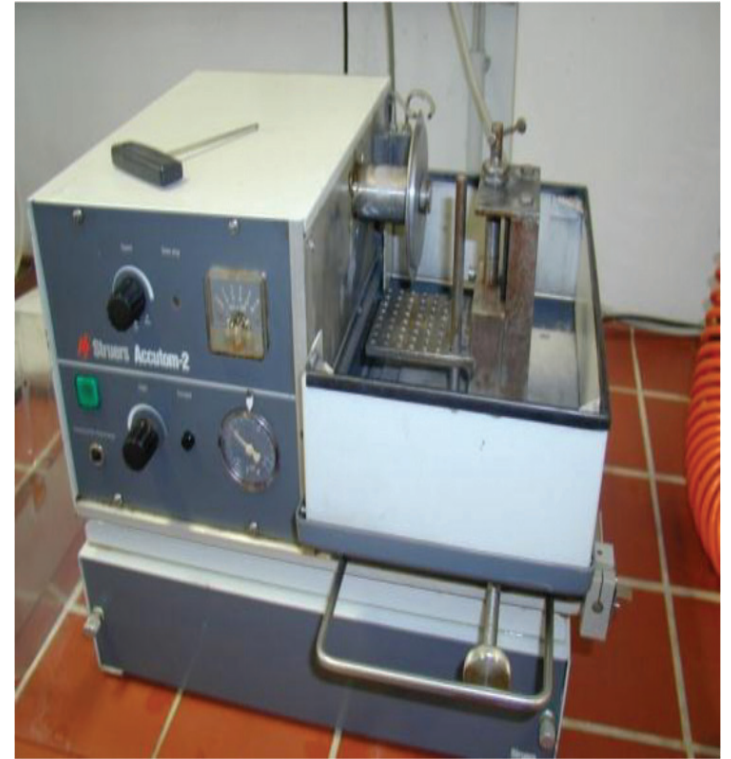

Figure 1: Diamond wheel machine.

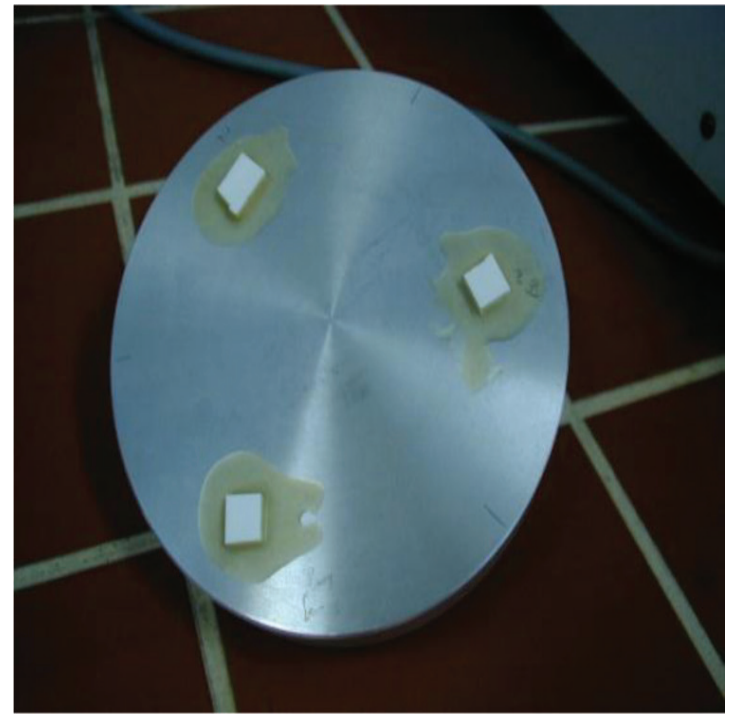

Figure 2: Mounting the specimen on upper disc of the polishing plate. 


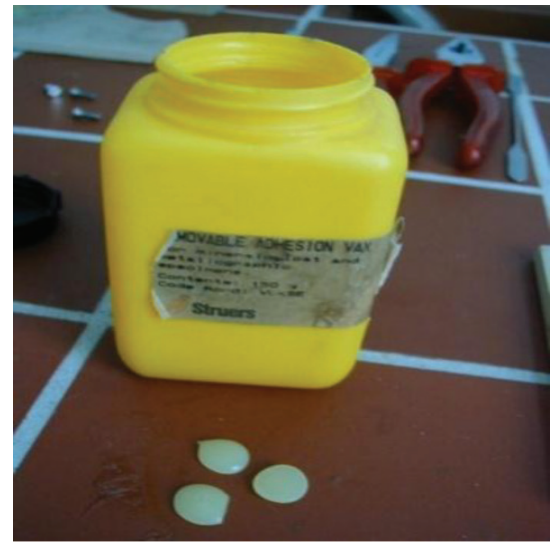

Figure 3: Example Commercial thermoplastic type of glue.

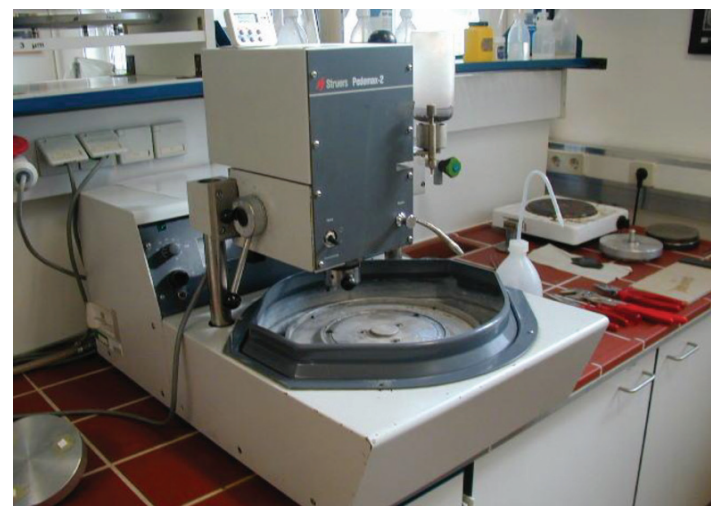

Figure 4: The polishing machine for ceramography. It is completed with upper and bottom disc to provide pressure during grinding and polishing.

The polishing was started with piano type of diamond grinding disc (Fig. 5), followed by serial polishing by using diamond powder (Fig. 6) with time and pressure variable listed in Table 1.

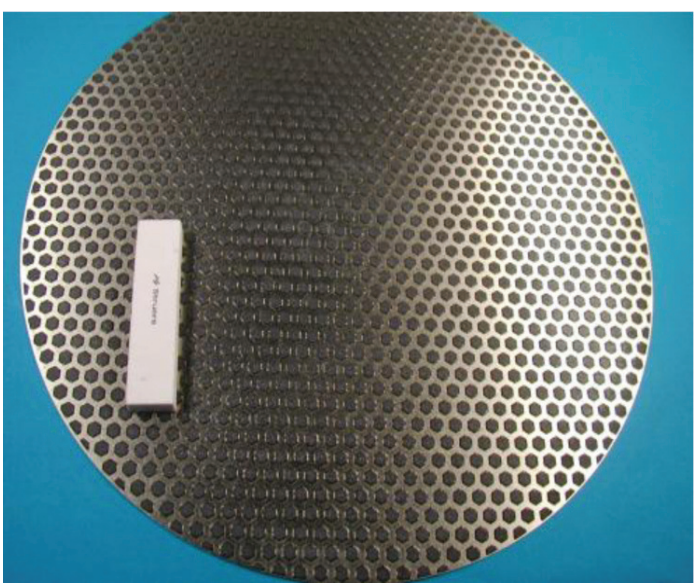

Figure 5: The piano type of diamond grinding.

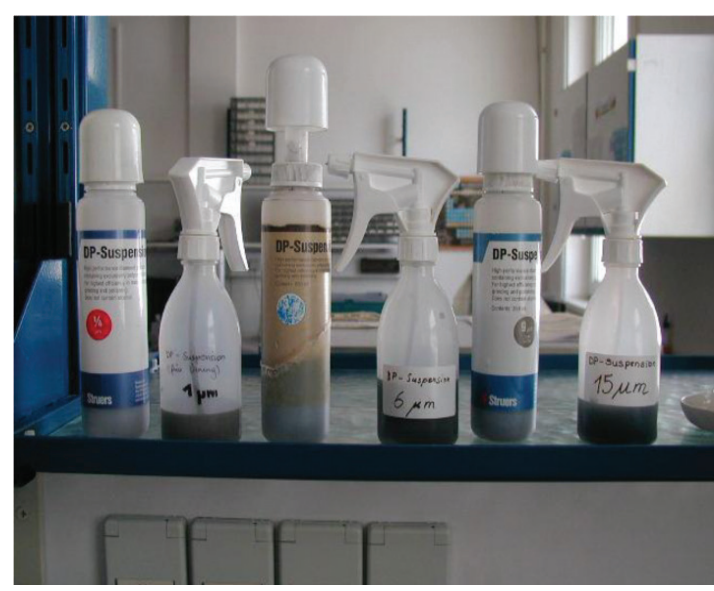

Figure 6: Serial of diamond powder for polishing.

TABLE 1: Serial steps of grinding and polishing for $\mathrm{Si}_{3} \mathrm{~N}_{4}$.

\begin{tabular}{|c|l|c|c|c|}
\hline Steps & Grinding/polishing method & Force level & RPM & Time (min) \\
\hline 1 & Diamond-Piano 220 & 4 & 150 & 5 \\
\hline 2 & Diamond-Piano 600 & 6 & 100 & 2 \\
\hline 3 & Diamond powder $15 \mu \mathrm{m}$ & 8 & 100 & 30 \\
\hline 4 & Diamond powder $9 \mu \mathrm{m}$ & 8 & 100 & 60 \\
\hline 5 & Diamond powder $6 \mu \mathrm{m}$ & 8 & 100 & 90 \\
\hline 6 & Diamond powder $3 \mu \mathrm{m}$ & 8 & 100 & 30 \\
\hline 7 & Diamond powder $1 \mu \mathrm{m}$ & 8 & 100 & 30 \\
\hline
\end{tabular}

Bright field and differential interference contras (DIC) or so called Nomarski in optical microscope is used to observe whether the final surface still contain scratch or not. Indentation test then was performed by using Vickers (Fig. 7) and Knoop (Fig. 8) indentation. By using Vickers, the value of hardness and fracture toughness and can be provided, and from Knoop indentation the value of modulus elasticity will be obtained. 


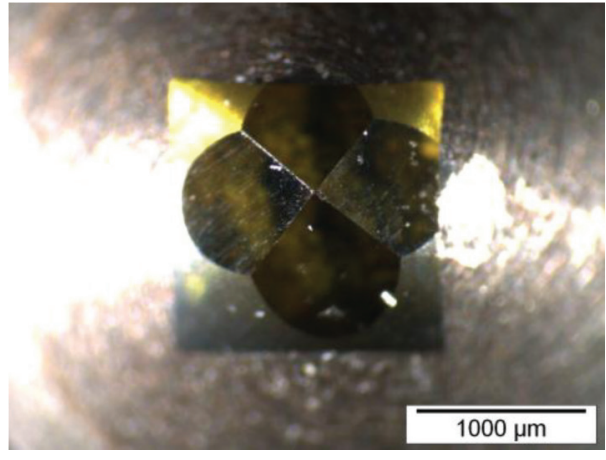

Figure 7: Vickers indenter.

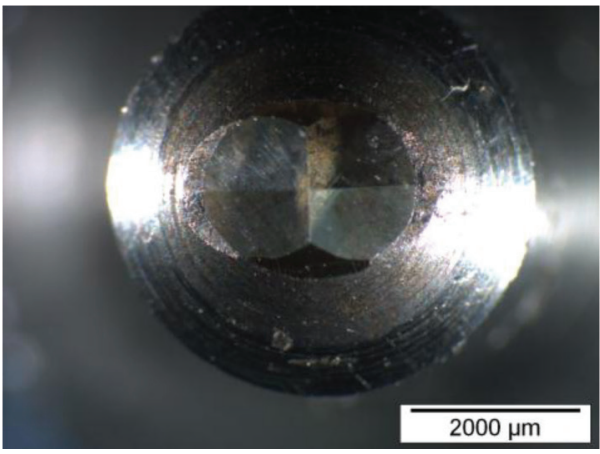

Figure 8: Knoop indenter.

Since $\mathrm{Si}_{3} \mathrm{~N}_{4}$ is ceramic material, this is meaning that etching process is dificult to be performed by using chemical solution. Plasma etching (Fig. 9) was introduced in this research to reveal the microstructure. Microstructure then was reveled by using both optical microscope and scanning electron microscope (SEM). This report will be completed with successful technique in revealing the defect such as crack and porosity by utilizing fluorescence dye penetrant with ultra violet (UV) source of light.

Provide sufficient detail to allow the work to be reproduced. Methods already published should be indicated by a reference. Only relevant modifications should be described.

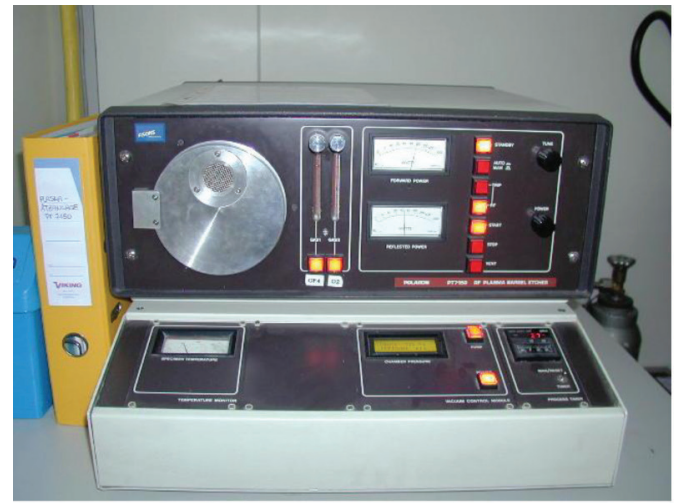

(a)

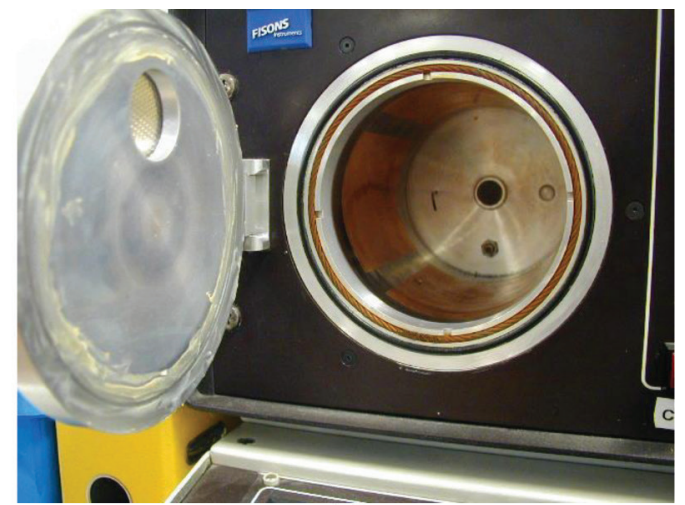

(b)

Figure 7: (a) Equipment for plasma etching, (b) Detail chamber for plasma etching.

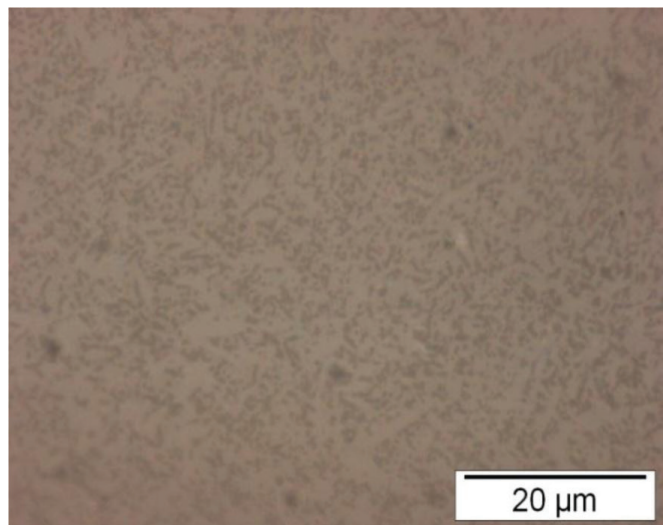

(a)

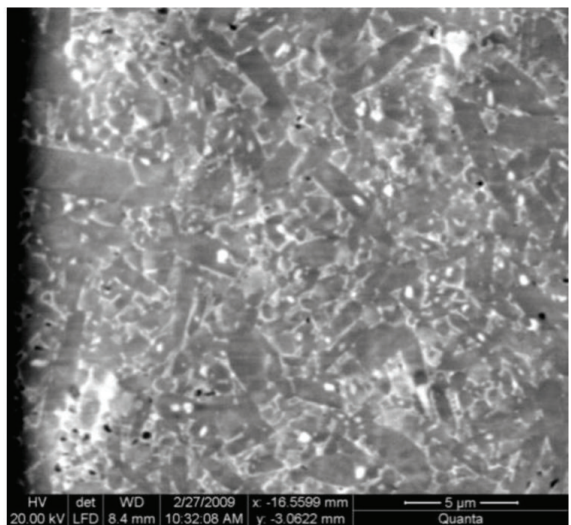

(b)

Figure 8: Microstructure after plasma etching of $\mathrm{Si}_{3} \mathrm{~N}_{4}$ (a). By using optical microscope. (b) Obtained from SEM. 


\section{Result and Discussion}

The grinding and polishing step that was developed in this research is successfully to obtain smooth surface without scratch. The microstructure that is found as can be seen in Fig. 8. Both optical and SEM picture are presented, and indicated that there are elongated grain as a typical of $\beta \mathrm{Si}_{3} \mathrm{~N}_{4}[3]$.

The Vickers hardness value was investigated based on ISO TC 206/SC N [4]. The load F that was applied was $10 \mathrm{~kg}$. The Vickers indentation was found valid as depicted in Fig. 9, with values found was14.2 GPa HV10, calculated by using Equation (1)[4] with $d$ is the arithmetic mean of two diagonal Vickers indentation.

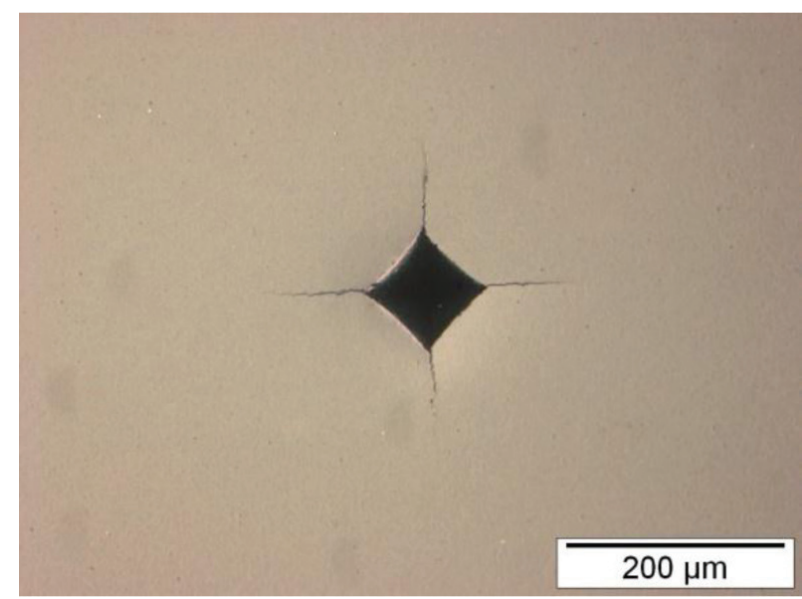

Figure 9: Vickers indentation of $\mathrm{Si}_{3} \mathrm{~N}_{4^{\prime}}$ load applied was $10 \mathrm{~kg}$.

$$
\mathrm{HV}(\mathrm{GPa})=0.001 \frac{2 \mathrm{~F} \sin \frac{136^{\circ}}{2}}{\mathrm{~d}^{2}}=0.001854 \frac{\mathrm{F}}{\mathrm{d}^{2}}
$$

The value of fracture toughness $(\mathrm{Kc})$ is also possible to be approached from indentation technique. The initial idea of using indentation for fracture toughness determination was introduce by Evan and Charles[5] that can be formulated from Equation (2).

$$
\mathrm{Kc} \Phi / \mathrm{H} \sqrt{\mathrm{a}}=0.15 \mathrm{k}(\mathrm{C} / \mathrm{a})^{-3 / 2}
$$

$\mathrm{H}$ is hardness, $\Phi$ the constrain factor $(\approx 3)$, the indentation crack length is $C$ should be related to the impression radius a, where $k$ is the correction $(k=3.2)$. By using the formula in Equation 2, the fracture toughness value is found $4.6 \mathrm{MPa} \cdot \mathrm{m}^{1 / 2}$.

It is interesting to be informed here that by using the result from Knoop indentation, the modulus elasticity can be approached by utilizing formula introduce by Marshal et. al. [5]. The method is based on measurement of elastic recovery of the in-surface dimensions of Knoop indentation. In the fully loaded state, the ratio of the diagonal dimensions, $a$ and $b$ of the contact area is defined by the indenter geometry $a / b=7.11$. However, on unloading, elastic recovery reduces the length of the shorter indentation diagonal, whereas the longer diagonal remains relatively unaffected. The extent of recovery depends on the hardness to modulus ratio. Therefore the distortion of the residual impression, characterized by the ratio of its dimensions, $b^{\prime} / a^{\prime}$, provide a measure $H / E$. The value of $E$ then can be calculated from Equation (3). 


$$
\mathrm{b}^{\prime} / \mathrm{a}^{\prime}=\mathrm{b} / \mathrm{a}=\alpha \mathrm{H} / \mathrm{E}
$$

With value of $b^{\prime} / a^{\prime}$ that was obtained from Knoop indentation as depicted in Fig. 10. The value of $\mathrm{E}$ that is calculated from Equation (3) was obtained $189.2 \mathrm{GPa}$.

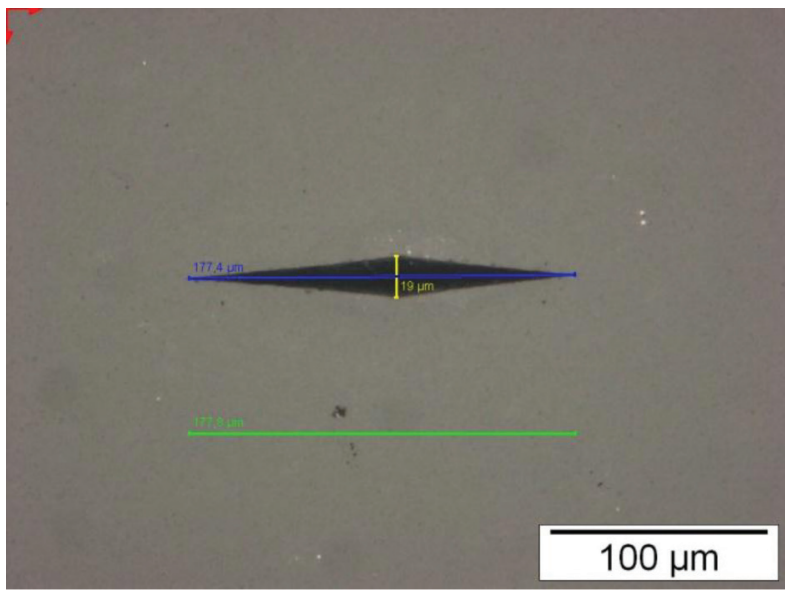

Figure 10: Measurement of long and short diagonal of Knoop indentation ( $\mathrm{HK}_{3}$ ) for modulus elasticity measurement.

The defect in the specimen was easily detected by using fluorescence dye penetrant as depicted in Fig. 11. Ultra violet source of light was applied for this purpose.

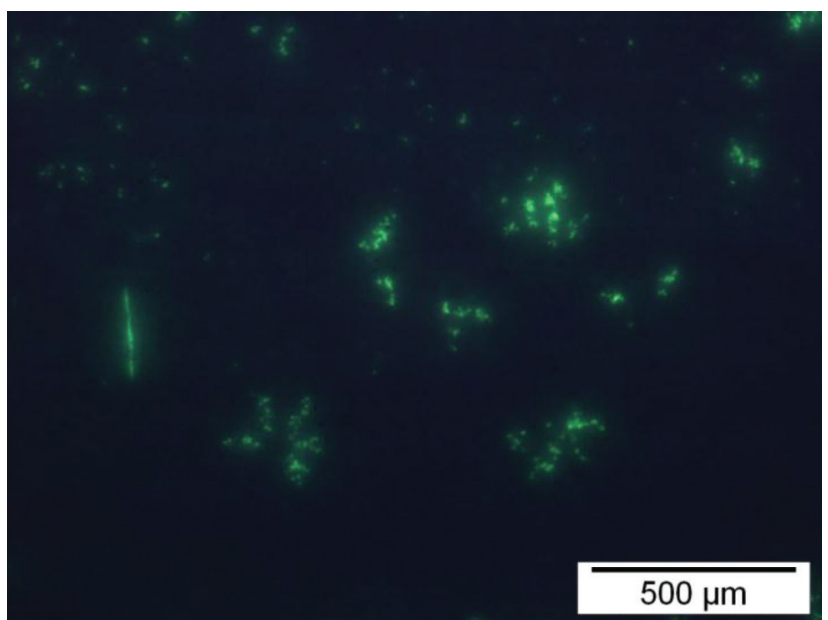

Figure 11: Illuminated green color is the defect in the specimen. This is obtained by immersed the specimen in the fluorescence dye penetrant. Observation was done with optical microscope under ultra violet source of light.

\section{Conclusion}

Ceramography technique on $\mathrm{Si}_{3} \mathrm{~N}_{4}$ that is developed in this research is successful to reveal the microstructure and indentation respond of the material $\mathrm{Si}_{3} \mathrm{~N}_{4}$. The hardness, fracture toughness and modulus elasticity of the specimen is also possible to be determined. The results showed that the Vickers hardness values found was 4.2 GPa HV10 and the fracture toughness value 
is found $4.6 \mathrm{MPa} \cdot \mathrm{m}^{1 / 2}$. With fluorescence dye penetrant under ultra violet source of light the defect in $\mathrm{Si}_{3} \mathrm{~N}_{4}$ was easily observed therefore is suitable to be proposed as a technique for testing the quality of silicon nitride component in nuclear application.

\section{Acknowledgment}

The author acknowledge Univ. Prof. Dr. Robert Danzer and Professor Tanja Lube of Institute for Structure and Functional Ceramic, Montanuniversitat, Leoben, Austria on supervising and facilitating this research and The Austrian Federal Ministry for Science and Research for financial support by awarding a technology grant southeast Asia (ACM-2007-01996) through program of ASEA-UNINET.

\section{References}

[1] Richerson, D. W., "Modern Ceramic Engineering, Marcel Dekker Inc.", New York, (1992).

[2] Chin, R. E., "Ceramography, ASM International, United State of America", (2001).

[3] Lube, T. and Dusza, J., "A Silicon Nitride Reference Material-A Testing Program of ESIS TC6", Journal of The European Ceramic Society 27 (2007). pp. 1203-1209, (2007)

[4] ISO TC 206/SC N, 2006, "Test Method for Hardness of Monolithic Ceramic at Room Temperature", ( 2006)

[5] Evan, A. G. and Charles, E. A., "Fracture Toughness Determination by Indentation", Journal of The American Ceramic Society, Vol. 59, No. 7-8, pp.371-372, (1976)

[6] Marshall, D. B., Noma T., and Evans, A. G., "A Simple Method for Determining Elastic Modulus to Hardness Ratios Using Knoop Indentation Measurements", Communications of The American Ceramic Society, Pp. C175-C176, (1982) 